\title{
Like Fire to Water: Building Bridging Collaborations between Disability Service Providers and Course Instructors to Create User Friendly and Resource Efficient UDL Implementation Material
}

\author{
Frederic Fovet, Tynan Jarrett, Heather Mole \& David Syncox, McGill University
}

\begin{abstract}
This study presents a post-secondary campus`experience with systematic and global promotion of Universal Design for Learning. It analyzes data collected over a 24 months period, relating to course instructors' responses to the framework, through the lens of the initial hypothesis that successes and failures in adoption might be explained by the existence of variables that act as facilitators or stressors in the eyes of the participants. It is argued that identifying these variables allows campuses to map winning conditions for the rapid adoption of UDL by course instructors, irrespective of institutional context and resources. Importantly the study highlights that the full identification of these factors requires the involvement and collaboration of not simply the disability service provider, but also the Teaching and Learning support unit and the equity and diversity office. The study argues that such a collaboration model is transferable to other institutions.
\end{abstract}

\section{Key Words}

Universal Design - diverse learners - inclusion - Higher Education - instructors - Disability Equity - diversity

\section{Introduction}

Confronted with the changing and varied nature of disability in Higher Education, campuses are becoming increasingly sensitive to the social model (Swain, French, Barnes \& Thomas, 2004). Many disability service providers are moving away from the 'accommodations' approach, to focus instead on introducing sustainable changes to the learning environment itself. Universal Design is therefore now the model of choice and seeks the implementation of winning conditions in the classroom, by widening access and eliminating the need for retrofitting (Burgstahler, 2008).

While conceptually this paradigm shift appears logical and seamless (McGuire \& Scott, 2002), in reality the transformation of service provision has created tension: it requires a willingness on the part of course instructors to examine their own practices; it is forcing disability service providers to redeploy staff who originally focused solely on student assistance so that they may assist faculty; it also forces new and innovative collaborations and requires the establishment of dialogue and openness between these sometimes uneasy partners; last and not least, the paradigm forces a reexamination of the notion of access, a domain that is no longer the sole preoccupation of disability service providers, but incorporates parallel concerns of equity and diversity in Higher Ed learning (Gradel \& Edson, 2010; Howard, 2004). 
This paper analyzes a campus' experience and data collection opportunities as it journeyed through this transition over a two year period. It highlights how UDL implementation requires an increased degree of collaboration with teaching staff and how this complex support itself must integrate input from disability service providers, equity and diversity services and teaching and learning support equally.

\section{What is UDL?}

The literature on UD in higher education is abundant and far ranging (Rose, Harbour, Johnston, Daley \& Abarbanell, 2006; Gradel \& Edson, 2010). The aim of the study was not necessarily to scrutinize the adoption of each detailed item of the universal design framework, but rather to identify variables which seemed to facilitate or hinder the implementation process with instructors. The research partners did not therefore, for this project, adopt a rigid or narrow definition of the theoretical model or reading of the literature; the intention was to identify the spirit of the proposed framework and examine the facilitators and stressors apparent in teacher feedback.

A key notion to retain concerning UDL is the idea that environments and practices can equally enable or disable individuals. In this sense, it takes the focus away from individual user characteristics to highlight instead the environment's own ability to widen or restrict access. The researchers see universal design as the procedural translation and application of the social model of disability (Swain, French, Barnes \& Thomas, 2004), and not as a stand-alone technique of access.

The other critical dimension in the definition of UD that the OSD emphasizes is the fact that it is seen as a sustainable, environment-focused framework to manage disabilities issues (Colorado State University, 2013). The links between sustainability and universal design are rarely explicitly described in existing literature but it seemed important to stress this facet as part of the partners 'endeavors: sustainability in teaching practices is indeed a value shared by all three units.

It is also important to remember that universal design in essence requires the course instructor to return to the conception phase of his or her process (Harrison, 2006). Too often discussions about UD implementation are limited to redundant debates that address end product applicability, rather than initial design. UD's origins as an architectural concept are important and implementing UD necessarily means revisiting processes and practices from the start, rather than trying to fix the unfixable. Similarly, UD implementation is a progressive exploration and transformation. There is no such thing as a fully UDL teaching. Teaching can be more or less UD on a wide spectrum of accessibility. It is important to realize how wide the UD goals are and that full attainment of the criteria is wishful thinking.

Much of the existing literature on UDL in higher education focuses on the implementation within the pedagogical context (Gordon, Gravel \& Schifter, 2009). Current findings are that instructors are not opposed to UD on principle; often it is resources issues and budgetary institutional pressures that are used as delaying tactics in implementation (Strange \& Banning, 2001). The nature of training in higher education is also often mentioned as an obstacle since teaching training and professional development is so rarely compulsory in any way in postsecondary. The literature also stresses the lack of awareness concerning disability research amongst course instructors: few are familiar with the social model of disability (McGuire, Scott $\&$ Shaw, 2004) but the demographics of disability service provision are often unknown to faculty as well (Gordon, Gravel \& Schifter, 2009). Finally the post-secondary literature highlights the 
fact that students 'expectations with regards to inclusion and mainstreaming often go unnoticed (Strange \& Banning, 2001).

\section{Context}

The experience of this campus was fairly unique in the sense that responsibility for the promotion of UDL across the campus did not lie solely with the disability service provide. UD promotion became, early on in the process, a sharing of expertise and the development of collaborative practices with regards to access. Examples of such collaborative efforts, which were the result of bridging efforts with the diversity and equity office as well as the teaching and learning unit, include: a keynote presentation concerning UDL at a pedagogical training day organized for teaching assistants; the delivery of a workshop on access and UDL, open to any employee of the institution, offered through the diversity office; the three way collaboration of all three units in the hosting of a meeting of the executive bodies of the university on UD; and finally the creating of a multi-stakeholder working group on the inclusion of diverse learners.

Ownership over the UD model was never seen as being restricted to the disability service provider and it is this experience that makes this trajectory unique. The benefits of UDL implementation have from the start been perceived and presented as affecting a wide spectrum of non-traditional learners extending far beyond the service users of the disability unit. It is also argued that it is this collaborative approach which has rendered the data collection that follows possible, by allowing a nuanced and complex array of perspectives on course instructors` reactions to the UDL implementation drive.

The introduction and development of UDL as a framework for inclusion was structured by the parties as comprising two distinct stages: (i) the strategic lobbying mostly geared towards campus partners and senior administration; this phase was planned to last 18 months and was completed on time, culminating with the presentation to the university's executive bodies; (ii) the second phase of the implementation is also due to last 18 months and targets course instructors and faculty; it represents the hands on implementation phase and is currently in progress. It is in the course of this second chapter of the journey that the data presented here was collected.

\section{Methodology}

The study presents the analysis of qualitative data collected from course instructors from retroactive feedback obtained during or at the end of UD professional development exercises. These forums have varied from the very large (such as the presentation to the executive bodies of the university) to more modest gatherings such as a round table of deans and faculty chairs; the data also originates from feedback given during UD workshops offered to staff. A large portion of the data analysed also emanates from individual correspondence which occurred during discussion between instructors and the disability service unit regarding modifications in the procedures of that office and its external messaging to faculty. In more recent instances, data has also been generated by ongoing consultancy work carried out by the disability unit for specific faculties towards the redesign of courses and evaluations in line with UDL principles. A significant degree of triangulation has occurred through this process and this constitutes a cornerstone of the qualitative processes used here: indeed the UD material has substantially evolved during the promotional drive, in light of continuing faculty feedback and reactions 


\section{Findings}

The data analysis sought to highlight stressors and facilitators which appeared in the feedback and might explain the variety of reactions generated towards UD amongst course instructors. The categories of variables identified are as follows:

\section{Stressors}

Lack of time, budgetary concerns and issues of depleted resources were often mentioned as a reason why UDL implementation is overly onerous on instructors. Instructors had the perception that the transformation would increase their burden of work and did not feel they would be supported in this process.

Instructors are unlikely to attempt UDL implementation when faculty leadership does not appear to value this process. Participants frequently brought up departmental and faculty values and priorities as a hindrance to the UDL implementation process.

Many myths and fears persist concerning the widening of access and are internalized by the teaching body at large. Such fears include perceptions that standards may be affected by a widening of access to learning or that a flood gate phenomenon involving a constant rise in requests from students will systematically follow the removal of conventional barriers in learning.

A core skills analysis is often absent from curriculum design. Without a clear and explicit understanding of what skills are essential within each course, a discussion pertaining to the removal of barriers becomes fraught with difficulties. This core issue was central to make of the discussion which occurred between the UDL implementation team and instructors.

There exist clear misconceptions about UDL amongst instructors. The model is often seen as a new concept, and this in itself creates resistance factors related to the management of change process. The researchers found that by identifying teaching and evaluation practices already adopted and integrated by the participants which were UDL in format, the discussion progressed from a push back to a process of validation. Similarly the triangulation process during data collection led to a re-emphasis of the links between UDL and existing literature on inclusion, differentiated teaching and multiple intelligences.

Many instructors report experiencing fears, if not threats, undermining their feeling of professional competence. UDL often for includes an element of IT innovation into teaching styles (Rose, Meyer \& Hitchcock, 2005). Teachers are often reluctant to use innovative tools and to integrate them into their teaching practices for fear that their poor mastery of the tool will make them appear unprofessional. This finding echoes some of the literature on integration of IT in teaching (Tabata \& Johnsrud, 2008).

Instructors are also concerned to see the 'expert' role of the disability service providers being seemingly eroded. UDL implementation requires them to become judge of the accessibility of their own curriculum and classroom and many participants are reluctant to take on that role. To a degree a culture of referral has been internalized by participants and the preference is to simply hand over the responsibility for access to another office.

\section{Facilitators}

A pre-existing core skills analysis within a faculty or department greatly increases the likelihood of a constructive dialogue between the instructors and the various partners concerned with access. Participants, from faculties where this exercise had historically been identified and carried out systematically, described a relative ease in approaching discussions on widening access and in devising alternate teaching or evaluation formats. 
A rich personalized dialogue with key students often leads to an increased awareness amongst instructors and to a willingness to explore UDL. Privileged relationships with students affected by disability seem to radically modify these individual's approach to the widening of access.

Access to user friendly and time effective tools is key. The UDL literature is large to the point of being daunting for all but the most committed of instructors. The availability of bite size tools significantly increases the likelihood that the framework will be tentatively explored. In the implementation effort examined here, triangulation with participants led to the selection of 2 minute videos as chosen format chosen for all instructor tools.

Ownership of the model is essential and it seems therefore extremely important to be able to create and promote a phenomenon of modelling by faculty for faculty. Using instructors in the UD videos was perceived as crucial to their impact. The UDL implementation drive on this campus led to the creation of a Dean's Working Group on UDL Implementation. The terms of reference of the group specifically identify and address the need to offer faculty the opportunity to gain ownership over the framework.

Validation and positive reinforcement of existing pedagogical practices leads to quick adoption. Once training and discussions begin by highlighting what is already UDL in the pedagogical practices in place (either on an individual or institutional scale), reactions become less defensive and links are quickly established between the UDL model and other teaching theories which inform course design.

The availability of tools that are subject specific became increasingly relevant in the discussions with instructors. Even when the framework was globally appealing, it seemed difficult to generate further proactive momentum if specific resources were not immediately available to tackle issues that pertained to specific learning environments. Topics raised by participants as needing specific attention included: UD in labs, UD and graduate supervision, UD and real world learning such as modern language acquisition, or evaluation of music performance, etc.

\section{Outcomes}

The findings allow the instantaneous creation of a 'stressors vs. facilitators' analysis grid which is immediately transferable to other campuses and Higher Ed environments and can serve to examine and interpret other UDL implementation processes or plans (Table 1. Stressor and facilitator summary). The identification of specific facilitators and stressors greatly simplifies the UDL implementation effort in the sense that it eliminates a great deal of passionate resistance and enables units focused on the development of inclusive pedagogy, such as the partners in this study, to deconstruct resistance into actionable items. In this specific context, the analysis led to rapid measures which were able to erode the stressors while building on the facilitators. Such tangible steps included:

(i) the selection of UD advocates and liaison personnel within each faculty; this measure was suggested by the data analysis but has not been implemented yet - all other measures listed have been implemented successfully;

(ii) the showcasing of existing UDL practices by key faculty personnel;

(iii) the increase in campus wide 'modelling' of UDL, through videos, press releases and features in campus and local media;

(iv) the use of short video resources as 'just-in-time' tools for instructors;

(v) the integration of UDL awareness and mastery as a tenure criteria in teaching portfolios; 
(vi) the introduction of UDL principles as criteria in teaching evaluation;

(vii) creation of a consultancy and support service for curriculum 're-design' along UDL principles;

(viii) the creation amongst instructors of a sense of ownership over framework through repatriation of the implementation drive to responsibility of faculty committee.

Importantly too, in terms of transferability of the experience to other campuses, the study highlights the importance of creating a collaborative reciprocal relationship between all the campus stakeholders invested in the development of inclusive pedagogy and the widening of access (Tegmark-Chita, Gravel, Serpa, Domings \& Rose, 2012). It is clear that the process of analyzing the variables affecting instructors' reactions to the UDL implementation was dependent on that collaboration being in place. This is an important lesson for any campus seeking to embark on this journey.

\section{Table 1. Stressors and Facilitators}

\section{Stressors}

(i) Lack of Time, budgetary concerns and depleted resources concerns

(ii) Lack of modeling, departmental support or integration in leadership objectives

(iii) Myths, fears and perceptions regarding the removal of conventional barriers

(iv) Absence of a core skills analysis

(v) Misconceptions about UDL

(vi) Fears and threats, relating to perception of professional competence

(vii) Concerned over "expert" role; preference to hand over responsibility

\section{Facilitators}

(i) A pre-existing core skills analysis within faculties and departments

(ii) A personalized relationship and rich dialogue between instructor and students

(iii) Access to user friendly and time effective tools

(iv) Ownership of the model

(v) Availability of subject specific tools

\section{References}

Bowe, F. G. (2000). Universal design in education: Teaching non-traditional students. Westport CT: Bergin \& Garvey. 
Burgstahler, S. E. (2008). Universal design in higher education. In S. E. Burgstahler \& R. C. Cory (Eds.), Universal design in higher education: From principles to practice (pp. 3-20). Cambridge, MA: Harvard Education Press.

Colorado State University (2013) Institutionalizing UDL: How to Implement UDL and Make It Sustainable! (WWW) http://accessproject.colostate.edu/presentations/udl/consortium/june_08/workshop.php (accessed on August 19th, 2013)

Gordon, D.T., Gravel, J.W., \& Schifter, L.A. (2009). A Policy Reader in Universal Design for Learning (pp. 209-218). Cambridge, MA: Harvard Education Press.

Gradel, K., \& Edson, A. J. (2010). Putting universal design for learning on the higher ed agenda. Journal of Educational Technology Systems, Vol. 38(2), pp. 111-121.

Harrison, E. (2006) Working with Faculty Toward Universally Designed Instruction: The Process of Dynamic Course Design, Journal of Postsecondary Education and Disability, Special Issue: Universal Design in Higher Education, Vol. 19 (2), pp. 152 - 162

Howard, K. L. (2004). Universal design for learning: Meeting the needs of all students. Learning and Leading with Technology, Vol. 31, pp. 26-29.

McGuire, J. M., Scott, S. S., \& Shaw, S. F. (2004). Universal design for instruction: The paradigm, its principles, and products for enhancing instructional access. Journal of Postsecondary Education and Disability, Vol. 17(1), pp. 10-20.

McGuire, J., \& Scott, S. (2002). Universal design for Instruction: a promising new paradigm for higher education. Perspectives, Vol. 28(2), pp. 27-29.

Rose, D.H. \& Gravel, J.W. (2010). Universal design for learning. In E. Baker, P. Peterson, \& B. McGaw (Eds.). International Encyclopedia of Education, 3rd Ed. Oxford: Elsevier.

Rose, D. H., Harbour, W. S., Johnston, C. S., Daley, S. G., \& Abarbanell, L. (2006). Universal design for learning in postsecondary education: Reflections on principles and their application. Journal of Postsecondary Education and Disability, Vol. 19(2), p. 17.

Rose, D. H., Meyer, A., \& Hitchcock, C. (2005) The Universally Designed Classroom: Accessible Curriculum and Digital Technologies. Cambridge, MA: Harvard Education Press.

Strange, C.C. and Banning, J.H. (2001) Educating by Design: Creating Campus Learning Environments that Work. San Francisco: Jossey-Bass.

Swain, J., French, S., Barnes, C., \& Thomas, C. (Eds.) (2004) Disabling Barriers Enabling Environments. 2d ed. London: SAGE. 
Tabata, L. \& Johnsrud, L. (2008). The Impact of Faculty Attitudes Toward Technology, Distance Education, and Innovation. Research in Higher Education, Vol. 49, pp. 625-646

Tegmark-Chita, M., Gravel, J.W., Serpa, M. deL. B., Domings, Y., \& Rose, D.H. (2012) Using the Universal Design for Learning framework to support culturally diverse learners, Journal of Education, Vol. 192(1), pp. 17-22 